\title{
ASPECTOS RELEVANTES DAS COLUNAS DE FLOTAÇÃO
}

\author{
M. L. M. de Oliveira ${ }^{1}$ e J. A. de Aquino ${ }^{2}$ \\ ${ }^{1} \mathrm{Dr}^{\mathrm{a}}$., Pesquisadora da MCE Consultoria e Engenharia Ltda. \\ mluciabh@gmail.com \\ ${ }^{2}$ Dr., Pesquisador do Centro de Desenvolvimento da Tecnologia Nuclear - CDTN \\ jaa@cdtn.br
}

Trabalho apresentado no XXI ENTMME, Natal-RN, novembro, 2005

\begin{abstract}
RESUMO
A flotação é um dos processos de concentração mais utilizados na indústria mineral, possibilitando o aproveitamento de minérios complexos e/ou de baixo teor de forma econômica e com rendimentos satisfatórios. A importância desse processo tem motivado o desenvolvimento de novos equipamentos dentre os quais se destaca a coluna de flotação. As melhorias substanciais das características dos concentrados obtidos nas colunas em diversas unidades industriais, operando com diferentes tipos de minérios, somadas ao melhor desempenho metalúrgico e à economia nos custos de capital e de operação, demonstram a importância desse equipamento para a indústria mineral. Tais fatores têm sido decisivos para a aplicação das colunas em processos de flotação, tanto para novos projetos, como para expansões industriais. O sucesso das instalações industriais de colunas de flotação depende substancialmente das bases consideradas no scale up e do projeto do equipamento. O primeiro passo consiste na realização de teste de flotação em uma unidade piloto que permita definir as condições de flotação e os resultados que serão obtidos. Os parâmetros definidos em escala piloto são aplicados a modelos matemáticos específicos que permitem o escalonamento e projeto final. Esses modelos assumem simplificações que acarretam diferenças na resposta metalúrgica das colunas industriais, quando comparadas aos resultados dos testes piloto. Além disso, as colunas de flotação são operadas freqüentemente de forma similar às células mecânicas convencionais sem considerar as diferenças entre esses equipamentos, principalmente no que se refere à geometria (relação altura/diâmetro efetivo), à adição de água de lavagem, a ausência de agitação mecânica e ao sistema de geração de bolhas, contribuindo para obtenção de rendimentos metalúrgicos inferiores aos esperados. Apresenta-se neste trabalho uma abordagem específica sobre os principais problemas encontrados na operação de colunas industriais.
\end{abstract}

Palavras-chave: flotação, coluna, scale up. 


\section{ASPECTOS RELEVANTES DAS COLUNAS DE FLOTAÇÃO}

\section{INTRODUÇÃO}

A flotação é um dos processos de concentração mais utilizado na indústria mineral, possibilitando o aproveitamento de minérios complexos e/ou de baixo teor de forma econômica e com rendimentos satisfatórios. A importância desse processo tem motivado o desenvolvimento de novos equipamentos dentre os quais se destaca a coluna de flotação.

Na década de 60, Boutin e Tremblay (1962) registraram uma patente referente à técnica de flotação em coluna. A partir de então, foram realizados diversos esforços no sentido de viabilizar a implantação dessa tecnologia em escala industrial, dentre os quais se destacam as aplicações realizadas pelo Dr. D. A. Wheeler (1966), considerado o pai da Coluna Canadense. Finalmente, em 1982 Coffinn e Miszczak relataram que as primeiras colunas de flotação industrial de sucesso foram instaladas em uma planta de concentração de molibdenita em Les Mines Gaspé no Canadá. Essas colunas foram utilizadas nos estudos hidrodinâmicos das seções de coleta e de limpeza conduzidos pelos pesquisadores Gleen Dobby e Juan Yianatos sob orientação do professor Finch na Universidade de McGill Canadá (Finch e Dobby, 1990).

As melhorias substanciais na qualidade dos concentrados obtidos nas colunas em diversas unidades industriais, operando com diferentes tipos de minérios, somadas aos ganhos no desempenho metalúrgico e à economia nos custos de capital e de operação, demonstram a importância desse equipamento para a indústria mineral. Tais fatores têm sido decisivos para a aplicação das colunas em processos de flotação, tanto para novos projetos, como para expansões industriais.

O sucesso das instalações industriais de colunas de flotação depende substancialmente das bases consideradas no scale up e do projeto do equipamento. O primeiro passo consiste na realização de teste de flotação em uma unidade piloto que permita avaliar a flotabilidade dos minerais de interesse frente a diferentes tipos e dosagens de reagentes e condições operacionais.

Os parâmetros definidos nos testes piloto são aplicados a modelos matemáticos específicos que permitem o scale up e projeto final. Esses modelos assumem simplificações que acarretam diferenças na resposta metalúrgica das colunas industriais, quando comparadas aos resultados dos testes piloto.

Outro aspecto importante a ser considerado para obtenção de resultados satisfatórios na escala industrial consiste na forma de operação das colunas, que diferem substancialmente das células mecânicas convencionais, principalmente no que se refere à geometria (relação altura/diâmetro efetivo), à adição de água de lavagem, a ausência de agitação mecânica e ao sistema de geração de bolhas.

Apresenta-se neste trabalho uma abordagem específica sobre os principais problemas encontrados na operação de colunas industriais.

\section{DESCRIÇÃO DA COLUNA}

Uma representação esquemática de uma coluna de flotação está apresentada na Figura 1. A polpa é alimentada a aproximadamente dois terços da altura total da coluna na seção de recuperação ou coleta. As partículas minerais interagem com as bolhas de ar ascendente, 
introduzido na base da coluna, resultando no processo de coleta das partículas hidrofóbicas. O agregado partícula-bolha formado é então transportado até a seção de limpeza, onde é contactado em contracorrente com a água de lavagem introduzida no topo da coluna. A água de lavagem tem o objetivo de promover a estabilidade e limpeza da espuma, eliminando as partículas carreadas por arraste mecânico. As partículas minerais hidrofóbicas coletadas constituem a fração flotada, sendo separadas das partículas hidrofílicas, que saem pela base da coluna e constituem a fração não flotada (Aquino et al in Luz et al, 2004).

As colunas industriais têm um diâmetro efetivo da seção transversal variando entre 0,3 e 4,5 metros, podendo ser adotadas seções retangulares ou circulares. Colunas com diâmetros efetivos superiores a 1,5 metros são normalmente compartimentadas através de baffles verticais, com o objetivo de minimizar os efeitos de "turbulência" interna. A altura total das colunas pode variar em função das características operacionais requeridas, notadamente dos tempos de residência exigidos, mas a maioria das colunas industriais tem uma altura variando entre 10 e 15 metros.

Basicamente, uma coluna é constituída das duas seguintes seções:

- Seção de Recuperação: compreendida entre o ponto de injeção de ar e a interface polpa-espuma. Sua função é recuperar o mineral a ser flotado, através de um contato eficiente entre as partículas minerais e as bolhas de ar.

- Seção de Limpeza: compreendida entre a interface polpa-espuma e o transbordo do material flotado. Nesta seção mantém-se constante a altura da camada de espuma, que é lavada através de um fluxo de água em contracorrente, eliminando as partículas hidrofílicas arrastadas. 


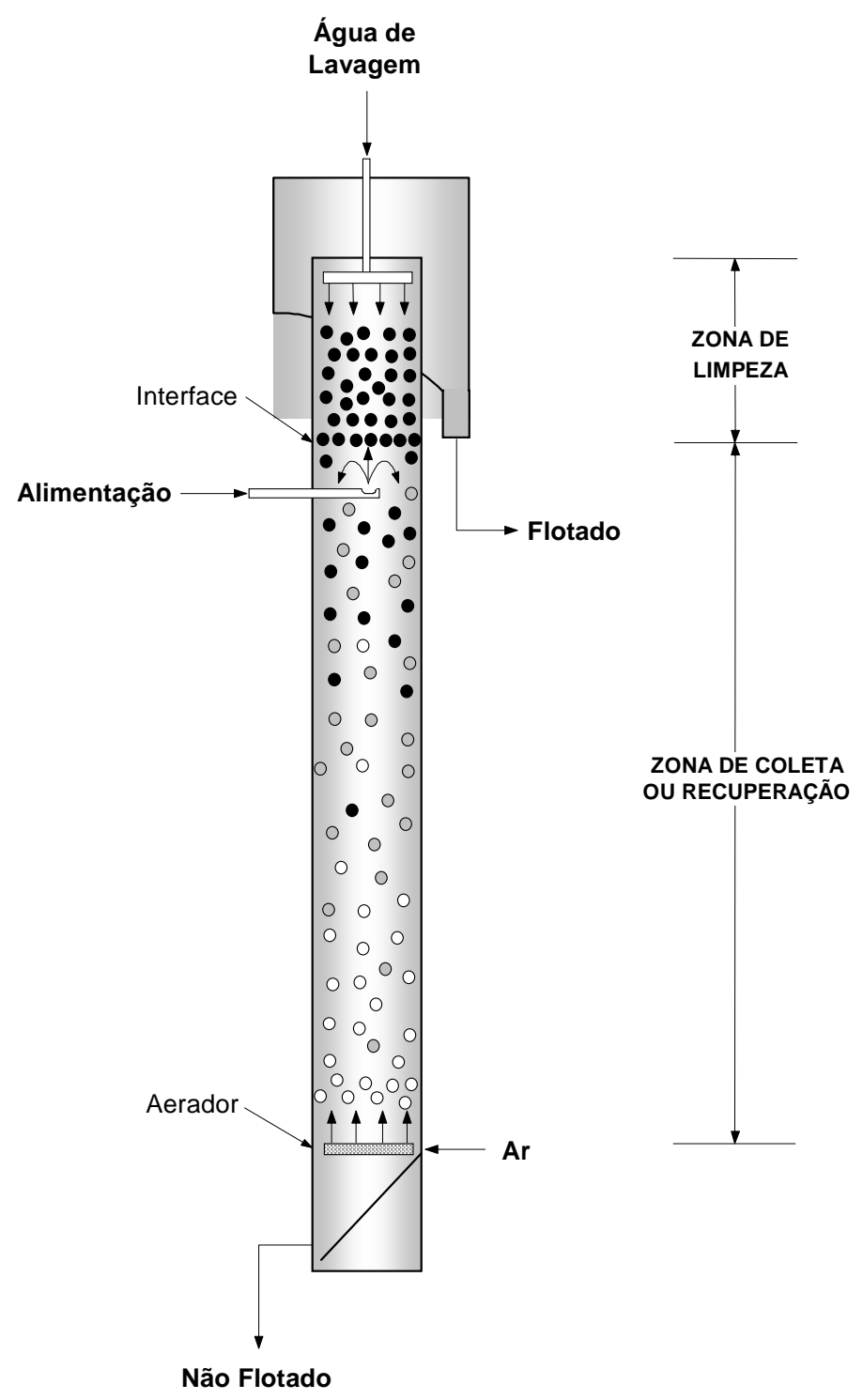

Figura 1 - Representação esquemática de uma coluna de flotação.

\section{PROBLEMAS QUE AFETAM O DESEMPENHO DAS COLUNAS INDUSTRIAIS}

O dimensionamento das colunas industriais é usualmente baseado em estudos realizados em escala piloto. Nesses estudos são avaliados os seguintes parâmetros:

> definição das condições de processo para obtenção dos resultados desejados;

$>$ teor e recuperação dos minerais de interesse;

$>$ efeito do tamanho das partículas;

$>$ efeito do tamanho das bolhas de ar;

> determinação da constante cinética dos minerais;

> capacidade de carregamento das bolhas de ar;

$>$ capacidade de transporte.

Para o scale up da coluna são mantidas as condições operacionais, o tamanho de bolhas e a velocidade superficial de ar definidos nos testes pilotos. 
Embora essas variáveis sejam mantidas constantes, a coluna industrial apresenta um desempenho metalúrgico inferior ao das colunas piloto principalmente no que se refere à constante cinética de coleta das partículas minerais e à recuperação na camada de espuma, resultando, freqüentemente, em recuperações do mineral de interesse no concentrado inferiores às obtidas no estudo piloto. As principais causas das diferenças no desempenho metalúrgico das colunas industriais são comentadas a seguir.

\subsection{Características operacionais}

O rendimento das colunas de flotação está normalmente relacionado com seu sistema de fluxo. Enquanto as colunas piloto, com uma relação altura/diâmetro elevada, operam em regime de fluxo próximo ao chamado "pistão", as colunas industriais operam entre o fluxo “pistão” e a mistura perfeita.

No fluxo pistão - também conhecido como plug flow - o tempo de residência de todas as fases, fluido e partículas minerais, é o mesmo, há um gradiente de concentração das partículas hidrofóbicas ao longo do eixo da coluna e o coeficiente de mistura, $\mathrm{N}_{\mathrm{D}}$, é próximo de zero. Por outro lado, no fluxo tipo mistura perfeita - ou perfect mixer - o líquido e os sólidos na seção de recuperação da coluna apresentam uma distribuição de tempo de residência $\tau$, a concentração das partículas é a mesma em qualquer ponto da seção de recuperação da coluna e o coeficiente de mistura tende a infinito. Para baixos tempos de residência, o teor da fração flotada é mais elevado e a recuperação é menor uma vez que as partículas minerais tiveram um tempo de residência inferior ao necessário para sua flotação. Em elevados tempos de residência o teor da fração flotada diminui porque essa condição favorece o arraste e a coleta de partículas hidrofílicas e menos hidrofóbicas, respectivamente. As células mecânicas operam em regime de mistura perfeita e, conseqüentemente, para reduzir os efeitos citados, são arranjadas em bancos constituindo tanques em série.

Recentemente, Yianatos et al (2000) realizaram medidas de distribuição de tempos de residência em colunas industriais de flotação utilizando traçadores radioativos. Foram utilizados Br-82 como traçador líquido e as partículas minerais não flotáveis com diâmetro de 40 a $60 \mu \mathrm{m}$ foram ativadas para serem usadas como traçadores sólidos. Os resultados obtidos mostraram que o tempo de residência médio da fase líquida foi de 10,7 minutos enquanto o das partículas sólidas foi de 8,9 minutos. Uma vez que o tempo de residência diminui com o aumento do tamanho das partículas, minérios com granulometria mais grossa terão tempo de residência menor, levando à recuperações mais baixas.

Mills et al. (1992), realizam estudo de distribuição de tempo de residência utilizando o modelo de tanques em série para coluna piloto de $50 \mathrm{~mm}$ de diâmetro e relação altura/diâmetro superior a 100. A análise dos resultados obtidos mostrou que a operação da coluna piloto era equivalente a 10 a 30 misturadores perfeitos em série. Por outro lado, a distribuição de tempo de residência de uma coluna industrial, utilizando o mesmo modelo, mostrou que a operação dessa coluna era equivalente a 1,2 a 1,9 misturadores perfeitos em série. Em função disso, a obtenção de níveis elevados de recuperação em um único estágio de flotação em coluna industrial é muito difícil.

\subsection{Compartimentação da coluna e calhas internas}

As colunas industriais processam grandes quantidades de minério e, conseqüentemente, têm dimensões significativamente superiores às das colunas piloto. A situação ideal de 
scale up seria a construção de " $\mathrm{n}$ " colunas com relações dimensionais similares às utilizadas nos testes piloto. Entretanto, essa alternativa é inviável economicamente devido aos custos de capital e de operação, principalmente considerando os custos de construção das colunas, aquisição de sistemas de instrumentação e a simplificação de circuitos. Em função disso, as colunas industriais apresentam relações diâmetro/altura significativamente diferentes, ou seja, inferiores às das colunas piloto. Como conseqüência dessa alteração nas relações dimensionais há uma elevação na turbulência na coluna levando a uma redução na qualidade da distribuição de ar e da água de lavagem, acarretando um contato menos efetivo entre as partículas minerais e as bolhas de ar. Para prevenir essas perdas, as colunas industriais de grandes dimensões são divididas em compartimentos de 1,0 a 1,5 metros de diâmetro efetivo através da utilização de baffles.

As colunas de flotação eram, inicialmente, compartimentadas apenas na seção de coleta, acima dos aeradores e abaixo da interface polpa espuma. A partir do modelamento da seção de espuma, observou-se a necessidade de divisão também da seção de espuma uma vez que as perdas de recuperação nessa seção eram significativas, principalmente pelo efeito da mistura que favorece a coalescência das bolhas e consequentemente a descoleta das partículas hidrofóbicas. As colunas foram então construídas com baffles nas seções de recuperação e de limpeza e abertas na região dos aeradores e de alimentação de polpa. Amostragens realizadas ao longo do perímetro de transbordo desse tipo de coluna mostraram que havia diferença no teor do mineral de interesse no concentrado. Nesses testes, foi observada uma significante diferença entre os níveis dos compartimentos. Posteriormente foram construídas colunas divididas por baffles em toda a sua extensão com alimentações e aeradores independentes por compartimento. Embora a compartimentação dessas colunas tenha acarretado uma significativa redução da mistura, o controle de nível entre compartimentos tornou-se desbalanceado, acarretando reduções na recuperação e aumento no consumo de reagentes.

Em ambos os casos, para prevenir as perdas de teor e recuperação em função das diferenças de pressão nos compartimentos, torna-se de fundamental importância o balanceamento local entre as seções na região da interface polpa/espuma. Atualmente têm sido construídas colunas com grandes diâmetros sem utilização de baffles, aplicadas para concentração de minério de ferro. Entretanto, ainda não se tem notícia de estudos sistemáticos realizados nessas colunas.

Em grandes colunas o comprimento das calhas para o transbordo da espuma deve ser aumentado uma vez que o perímetro não cresce proporcionalmente ao aumento do volume da coluna. Em função disso a utilização de calhas internas é necessária. Essas calhas, além de serem de fundamental importância para garantir o rendimento das colunas industriais, garantem também que a maior distância horizontal a ser percorrida por uma bolha mineralizada até o seu transbordo não será maior que 1,0 metro.

\subsection{Distribuição de água de lavagem}

A água de lavagem adicionada na camada de espuma tem três funções básicas:

> substituir a água de alimentação na fração flotada minimizando o arraste hidráulico de partículas hidrofílicas;

$>$ aumentar a altura e a estabilidade da camada de espuma;

$>$ reduzir a coalescência das bolhas através da formação de um packed bubble bed. 
A utilização da água de lavagem permite a obtenção de maior seletividade no processo de flotação sem perdas significativas de recuperação (Yianatos et al, 1988). A eficiência da água de lavagem está diretamente relacionada com a sua distribuição que deve abranger toda a área da seção transversal da camada de espuma sem prejudicar o transbordo do material flotado.

Os distribuidores de água de lavagem podem ser classificados em externos e internos. O distribuidor externo é instalado acima da camada de espuma e apresenta as vantagens de estar protegido de entupimento por partículas sólidas e de permitir a sua inspeção visual durante a operação. Entretanto, apresenta as desvantagens de requerer uma vazão maior de água para manter a relação entre a velocidade superficial de bias e da água de lavagem $\left(\mathrm{J}_{\mathrm{B}} / \mathrm{J}_{\mathrm{W}}\right)$ constante e de reduzir a concentração de sólidos no material flotado. O distribuidor interno é instalado abaixo do transbordo da espuma e apresenta a vantagem de ser mais eficiente e produzir um material flotado com maior concentração de sólidos. Como desvantagens podem ser citadas a inspeção mais difícil, o aumento dos entupimentos dos orifícios e a obstrução de parte da área transversal da coluna. Os distribuidores internos são geralmente instalados entre 10 e 20 centímetros abaixo do nível do transbordo.

As dificuldades de inspeção e desobstrução dos orifícios dos distribuidores internos de água de lavagem têm levado a operação em condições que acarretam perdas principalmente da seletividade do processo de flotação. Da mesma forma, os distribuidores externos tipo tanque também apresentam entupimento dos orifícios, tanto devido à baixa qualidade da água quanto pela deposição de corpos estranhos na superfície.

\subsection{Distribuição de ar}

A vazão de ar é uma das variáveis mais importantes no processo de flotação em coluna e tem um efeito significativo sobre a recuperação do mineral flotado. Dentro dos limites de estabilidade da coluna, a recuperação do mineral flotado é normalmente crescente com o aumento da vazão de ar até atingir o seu valor máximo. Este ganho na recuperação deve-se ao aumento do número e área superficial total de bolhas introduzidas na coluna. Entretanto, um acréscimo significativo da vazão de ar pode prejudicar o processo de flotação devido à turbulência ou formação de espuma na seção de recuperação da coluna.

A velocidade superficial do ar (Jg) é definida como sendo a relação entre a vazão de ar (Qg) em CNTP e a área da seção transversal da coluna (Ac). Para condições típicas de operação a velocidade superficial do ar situa-se entre 1 e $3 \mathrm{~cm} / \mathrm{s}$.

$$
\mathrm{J}_{\mathrm{g}}=\frac{\mathrm{Q}_{\mathrm{g}}}{\mathrm{A}_{\mathrm{c}}}
$$

Um gerador de bolhas eficiente é aquele capaz de gerar bolhas de 0,5 a 2,0 mm de diâmetro, com a velocidade superficial de ar entre 1,0 e 3,0 cm/s e hold up do ar de 15 a 20\%. Além disso, deve ter manutenção mecânica e operação fácil e ser construído com materiais resistentes ao desgaste (Luz et al, 2004).

Os tipos de aeradores atualmente utilizados em colunas industriais de flotação consistem basicamente de lanças perfuradas alimentadas com uma mistura de água e ar sob pressão 
ou de lanças com um só orifício alimentado somente com ar. Estes aeradores apresentam como principais vantagens a possibilidade de remoção, inspeção e substituição dos injetores com a coluna em operação e a geração de bolhas menores e mais uniformes.

Os orifícios dos aeradores pelos quais passa a mistura água-ar ou somente ar estão sujeitos a condições drásticas de operação em função da corrosão causada pela abrasão devido às elevadas velocidades. Em função disso, ocorre o desgaste da superfície levando a um aumento no seu diâmetro e conseqüentemente, do tamanho das bolhas formadas. Por outro lado, os resíduos sólidos presentes na água dos aeradores de lanças perfuradas podem acarretar a obstrução de parte dos orifícios contribuindo para uma má distribuição das bolhas de ar. Uma vez que a constante cinética de coleta das partículas está intimamente relacionada com o tamanho e a distribuição das bolhas de ar, em colunas industriais podem ocorrer perdas de recuperação por falta de manutenção desses equipamentos.

\subsection{Controle}

A principal desvantagem da coluna de flotação com relação às células mecânicas convencionais é a variação dos resultados obtidos, principalmente no que se refere à recuperação. Essa variação pode ser atribuída à menor flexibilidade da coluna em relação à absorção de variações inerentes ao processo. Nos testes realizados em escala piloto, usualmente é utilizada uma amostra com características e granulometria constantes, e as taxas de fluxo de alimentação e produtos da coluna são mantidas estáveis. Além das variações normais na composição de alimentação e dos fluxos e da necessidade de manutenção periódica dos aeradores, as colunas industriais são também afetadas pelas seguintes fontes de problemas:

> calibração e manutenção inadequada da instrumentação;

$>$ distribuição inadequada das bolhas de ar e da água de lavagem;

$>$ diferença entre a profundidade da espuma nos diversos compartimentos;

$>$ falta de robustez da estratégia de controle.

O objetivo básico do controle é manter a operação da coluna em condições estáveis. Isso pode ser alcançado controlando automaticamente o nível da interface polpa-espuma (Bergh e Yianatos, 1993). Os fluxos de ar e de água de lavagem são também controlados de forma a melhorar o desempenho metalúrgico das colunas. São utilizadas duas estratégias de controle. A primeira consiste no controle do nível da interface através da regulagem da taxa de fluxo da fração não flotada da coluna, mantendo a vazão de água de lavagem constante. Essa estratégia é a mais simples e a de menor custo, entretanto apresenta a desvantagem de permitir a operação em condições de bias negativo. A segunda estratégia consiste do controle de nível atuando sobre a vazão de água de lavagem enquanto a vazão de rejeito é regulada para manter constante a relação entre os fluxos volumétricos de rejeito e da alimentação. Essa alternativa apresenta custo mais elevado e resposta mais lenta.

Atualmente têm sido desenvolvidas estratégias de medição direta do teor do mineral de interesse no concentrado, e atuação nas vazões de ar e de água de lavagem e nível da interface para controlar o desempenho metalúrgico da coluna em uma faixa de operação pré-estabelecida. Essa alternativa permite o desenvolvimento de sistemas especialistas para controle das colunas de flotação. 
Ressalta-se que, devido ao mau funcionamento da instrumentação de diversas colunas industriais, por falta de calibração ou de manutenção, são observadas perdas significativas de rendimento metalúrgico.

\section{CONCLUSÃO}

As colunas industriais apresentam, freqüentemente, um desempenho metalúrgico inferior ao das colunas piloto principalmente no que se refere à constante cinética de coleta das partículas minerais e à recuperação na camada de espuma, resultando em recuperação do mineral de interesse no concentrado inferior à obtida no estudo piloto.

Nesse trabalho foram revisados os seguintes aspectos que influenciam o rendimento metalúrgico das colunas de flotação: sistemas de fluxo, a compartimentação da coluna utilizando baffles, as calhas internas para coleta da fração flotada, a regularidade da distribuição do ar e da água de lavagem e a qualidade da instrumentação e da estratégia de controle.

\section{REFERÊNCIAS BIBLIOGRÁFICAS}

Bergh, L.G. and J.B. Yianatos. Control alternatives for flotation columns. Minerals Engineering, Vol.6, No.6, 631-642, 1993

Boutin, P. and Tremblay, R., Canadian Patents Nº 680576 and 680654, 1962.

Coffinn, V.L. and Miszczak, J. Column flotation at Mines Gaspé, $14^{\text {th }}$ Int. Mineral Processing Congress, paper IV.21, Toronto, Canadá, 1982.

Finch, J.A. and Dobby, G.S. Column flotation, Pergamon Press, $1^{\text {st }}$ Ed., 1990.

Luz, Adão B et al, Tratamento de Minérios, 4 a ed, Rio de Janeiro, CETEM, 459-494, 2004.

Mills, P.J.T, J.B. Yianatos and C.T. O’Connor. The effect of particle size on the mixing characteristics of a flotation column. Minerals Engineering, Vol.3, Nº, 567-576, 1992.

Wheeler, D.A. Big flotation column mill tested, Eng.\& Mining Journal, Vol.167, N¹1, pp. 98-100, 1966.

Yianatos, J.B., Díaz, F. Y Rodríguez, J., Medición de la distribución de tiempo de residencia en equipos de flotación industrial, Anales XIV Congreso Chileno de Ing. Química, U. de Santiago, Chile, 26-23 Octubre, 2000.

Yianatos, J.B., J.A. Finch and A.R. Laplante. Selectivity in column flotation froths. Int. Journal of Mineral Processing, 23, 279-292, 1988. 